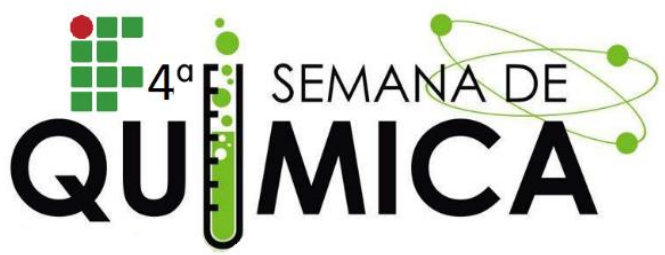

\section{DETERMINAÇÃO DOS TEORES DE MACROELEMENTOS EM AMOSTRAS DE CATCHUP E MAIONESE COMERCIAIS}

SILVA, L. G. (IFRN), LOPES, R.C.L.(IFRN), SOUZA, I. R. S. (IFRN), CORCINO, F. H. C. (IFRN), SILVA, C. L. B (IFRN), DANTAS, A. N. S. (IFRN)

Palavras Chave: Catchup, maionese, macroelementos.

\section{INTRODUÇÃO}

Produtos industrializados são amplamente consumidos em função de sua praticidade. Assim, o catchup e a maionese fazem parte do grupo dos molhos industrializados. ${ }^{[1]}$ De acordo com a ANVISA, a maionese consiste em um produto cremoso produzido através de água, ovos e óleos vegetais, enquanto o catchup é um molho obtido a partir de polpa de tomates. Em ambos os molhos, são dicionados ingredientes como conservantes, que são ricos em sódio. ${ }^{[2,3]}$ Com base nisso, o conhecimento acerca dos teores de macro elementos presentes nesses alimentos é de grande importância para a saúde da população ${ }^{[1]}$. Desta forma, o presente trabalho tem como objetivo quantificar os teores de sódio, potássio e lítio em amostras de catchup e maionese de diferentes fabricantes.

\section{METODOLOGIA}

Foram adquiridas amostras de catchup e maionese de diferentes fabricantes $(n=4)$. As amostras foram submetidas a um processo de decomposição por via úmida (1g de amostra $+3 \mathrm{~mL}$ $\mathrm{HNO}_{3}+2 \mathrm{~mL}$ de $\mathrm{H}_{2} \mathrm{O}_{2}$ ) assistida por radiação infravermelho. A mistura submetida a um programa de aquecimento (tempo de 30 minutos) utilizando um Protótipo de digestão IR controlo via Arduino. Após os processos de mineralização das amostras, foram determinados os teores de sódio, lítio e potássio por meio de Fotometria de Emissão com chama (BFC-Benfer).

\section{RESULTADOS E DISCUSSÕES}

Após o processo de digestão das amostras, os digeridos de catchup apresentaram aspecto límpido, com uma pequena coloração avermelhada na solução. Já as amostras de maionese, também apresentaram um aspecto límpido e com ausência de cor no digerido final. Após esta etapa, foram quantificados os teores dos macroelementos. Os resultados obtidos estão mostrados na Tabela 1.

Tabela 1- Teores de sódio potássio e lítio obtidos na análise dos catchups.

\begin{tabular}{|c|c|c|c|c|}
\hline \multirow{4}{*}{ CATCHUP } & \multirow{2}{*}{ FABRICANTE } & \multicolumn{3}{|c|}{ TEORES $\mathbf{~ m g ~ g ~}^{-1}$ ) } \\
\cline { 2 - 5 } & & $\mathbf{N a}$ & $\mathbf{L i}$ & $\mathbf{K}$ \\
\hline & $\mathrm{A}$ & 2,2 & $<L D$ & 0,9 \\
\cline { 2 - 5 } & $\mathrm{B}$ & 2,4 & $<L D$ & 1,5 \\
\cline { 2 - 5 } & $\mathrm{C}$ & 2,0 & $<L D$ & 2,96 \\
\hline & $\mathrm{D}$ & 1,7 & $<L D$ & 2,99 \\
\hline \multirow{3}{*}{ MAIONESE } & $\mathrm{E}$ & 0,9 & $<L D$ & 1,8 \\
\cline { 2 - 5 } & $\mathrm{F}$ & 0,9 & $<L D$ & 1,8 \\
\cline { 2 - 5 } & $\mathrm{G}$ & 1,8 & $<L D$ & 4,1 \\
\cline { 2 - 5 } & $\mathrm{H}$ & 1,2 & $<L D$ & 1,2 \\
\hline
\end{tabular}

Assim, o teor máximo observado de sódio em amostras de catchup e maionese foram respectivamente de $2,4 \mathrm{mg} \mathrm{g}^{-1}$ e $1,8 \mathrm{mg} \mathrm{g}^{-1}$. Já para potássio os teores máximos foram de $2,99 \mathrm{mg} \mathrm{g}^{-1} \mathrm{e}$ $4,1 \mathrm{mg} \mathrm{g}^{-1}$, respectivamente. Lítio não foi detectado nas amostras.

\section{CONCLUSÃO}

O trabalho permitiu desenvolver uma metodologia rápida e de baixo custo para quantificação dos macroelementos, permitindo obter uma informação essencial para o consumidor deste tipo de alimento.

\section{REFERÊNCIAS}

[1] OLIVEIRA, Anna Gabriella da Silva. et al. Os sachês de catchup e maionese como tema gerador no ensino de funções químicas inorgânicas. Revista Ibero-americana de Educação. n.ㅇ 56/4, p 2-3. 15/11/11.

[2] BRASIL. AGENCIA NACIONAL DE VIGILANCIA SANITÁRIA. Resolução №. 276 de 22 de Setembro de 2005. Disponível em: <http://www.pelotas.rs.gov.br/> Acesso em 07/08/2016.

[3] HONORATO, Karin. Consumo exagerado de sódio prejudica a saúde. Disponível em:<http://g1.globo.com/>Acesso em:07/08/2016. 